\title{
ATENÇÃO INTEGRAL À SAÚDE DO IDOSO: ASPECTOS NUTRICIONAIS NA LONGEVIDADE
}

\section{Laura Corrêa Ferraz'; Aline Fernandes²; Julia Prevedello Rossato³; Maria Helena Gehlen 4 .}

\section{RESUMO}

Objetivou-se descrever os aspectos nutricionais relacionados a ingesta de frutas cítricas, com um estímulo a longevidade com funcionalidade em uma instituição de longa permanência para idosos. Trata-se de uma atividade de ensino e extensão desenvolvido no decorrer das aulas teórico-práticas da disciplina de Atenção Integral à Saúde do Idoso, na cidade de Santa Maria, Rio Grande do Sul no primeiro semestre de 2021. Foi possível evidenciar que o estímulo da longevidade com funcionalidade se relaciona com o aspecto nutricional principalmente com os alimentos ingeridos como as frutas cítricas. Conclui-se que o estado nutricional saudável dos longevos impacta de forma significativa e positiva no processo de envelhecimento.

Palavras-chave: Extensão; Longevo; Nutrição; Senescência.

Eixo Temático: Atenção Integral e Promoção à Saúde.

\section{INTRODUÇÃO}

O processo de envelhecimento, conhecido como senescência, é um progresso natural com diminuição da reserva funcional dos indivíduos onde em condições normais essas modificações não provocam nenhuma adversidade. Em casos de sobrecarga do corpo, como doenças ou estresse emocional, pode acarretar condições patológicas associadas ao processo de envelhecimento, denominado como senilidade. Evidencia-se que o estilo de vida ativo e saudável pode minimizar os efeitos do processo de senescência (BRASIL, 2006). 
Segundo o IBGE (2017), no Brasil, estima-se que existam cerca de 30,2 milhões de idosos. Em vista disso, é necessário que se tenha estratégias políticas, econômicas e sociais para lidar com o aumento da população idosa, promovendo qualidade de vida, minimizando incapacidades físicas ou necessidades de cuidados especiais, auxiliando assim o aumento da expectativa de vida saudável para a população longeva (SOUZA, et al, 2016).

Ressalta-se a importância da contribuição dos diversos setores da sociedade para o processo de envelhecimento não ser marcado pelo aumento das demandas sociais e econômicas, resultantes de incapacidades e doenças crônicas não transmissíveis, implicando na autonomia e independência dos idosos. Práticas envolvendo nutrição, atividade física, comportamento preventivo e boas relações sociais promovem uma boa qualidade de vida a pessoa idosa (SOUZA, et al, 2016).

O estado nutricional do idoso é um relevante aspecto para o desempenho adequado da saúde, em casos nos quais a nutrição não está ocorrendo de forma correta podendo resultar em casos de obesidade, desnutrição, doenças crônicas não transmissíveis, fatores que influenciam no perfil de morbimortalidade, acarretando redução da qualidade de vida, aumento de infecções e mortalidade (PEREIRA, SPYRIDES, ANDRADE, 2016).

Neste sentido, o estado nutricional é um preditor de longevidade com funcionalidade. A longevidade foi contextualizada pelo explorador Dan Buettner que descobriu os cinco lugares do mundo, denominando-as de Zonas Azuis (Blue Zone), onde os indivíduos vivem vidas mais longas e saudáveis. O autor cita que o princípio está nas escolhas alimentares, na qual a maioria dos residentes da zona azul tem fácil acesso a frutas e vegetais de origem local, de preferência sem pesticidas e cultivados organicamente.

A busca por hábitos alimentares saudáveis influência de forma positiva no processo de envelhecimento, visto que, a ingestão de alimentos naturais e ricos em nutrientes consumida de maneira adequada garante aos indivíduos não apenas maior longevidade, mas também felicidade, qualidade de vida e satisfação pessoal, promovendo bem-estar ao idoso bem como prevenindo futuros agravos à saúde (AIRES, et al, 2019). 
Entende-se que a ação extensionista no Lar das Vovozinhas, sob o olhar das semelhanças culturais e sociais, possa contribuir para a melhoria da saúde, sociabilidade e promoção da qualidade de vida das idosas durante o período pandêmico, a partir da compreensão deste fator interveniente nos agravos nutricionais associado ao isolamento social. Nessa perspectiva, o presente trabalho tem por objetivo relacionar os aspectos nutricionais das frutas cítricas ao comportamento comum nas Blue Zone, sua influência na longevidade e assistência no combate ao distanciamento social.

\section{METODOLOGIA}

Trata-se de uma atividade de extensão que integrou o ensino desenvolvido no decorrer das aulas teórico-práticas e extensionistas da disciplina de Atenção Integral à Saúde do Idoso, na cidade de Santa Maria, Rio Grande do Sul.

As atividades foram desenvolvidas no primeiro semestre de 2021, por três acadêmicas do quinto semestre do Curso de Enfermagem, da Universidade Franciscana. A ação desenvolvida, juntamente com a apresentação no Seminário Blue Zone, contou como atividade avaliativa na disciplina.

A atividade de extensão integrada ao ensino se caracteriza em texto acadêmico descrevendo uma dada experiência que possa contribuir de forma relevante para a atuação profissional em geriatria. Destaca-se por ser uma vivência profissional considerada importante para a formação dos futuros profissionais da enfermagem assim como para qualidade de vida das longevas do Lar. Contribui com o compartilhamento de conhecimentos e vivências, pesquisa e a promoção e prevenção da saúde para a melhoria do cuidado de enfermagem.

A vivência teórico-prática foi realizada em quatro momentos distintos. $O$ primeiro momento caracterizou-se pela escolha da temática, segundamente a busca de referencial teórico sobre o tema elegido não só para elaboração deste artigo como também a ação desenvolvida para o Lar das Vovozinhas. No terceiro momento, foi produzido uma cesta composta por frutas cítricas, como laranja, 
bergamota e limão, com receitas de sucos para proveito de seus benefícios pelas longevas da instituição de longa permanência.

De tal modo, no quarto momento, discutido os resultados da ação extensionista, sendo estes socializados em um seminário denominado de Blue Zone.

\section{RESULTADOS E DISCUSSÕES}

A ação extensionista no Lar das Vovozinhas foi realizada em quatro etapas: definição da temática, escolhido pelas integrantes do grupo na disciplina de Atenção Integral à Saúde do Idoso, na cidade de Santa Maria, Rio Grande do Sul, execução da ação prática, sendo elaborado uma atividade encaminhada para o Lar das Vovozinhas e escrita acadêmica interligando o tema com o ato.

Segundo Aires (2019), a prática alimentar e estilo de vida possui enorme relevância no processo de envelhecimento, dentre esses hábitos tem-se a escolha correta dos alimentos logo, os comportamentos adquiridos pelos longevos devem valorizar elementos que contribuam para o bem-estar pessoal e que promova redução da ocorrência de doenças e outros agravos à saúde.

Ele cita que o consumo de frutas diariamente é essencial, pois estes alimentos são fontes de fibras que atuam na melhora da função gastrintestinal, além de auxiliar na redução da probabilidade de surgimento de doença coronariana, hipertensão arterial sistêmica, diabetes mellitus tipo 1 e 2, obesidade e câncer em geral.

Ademais, as frutas cítricas, por exemplo a laranja e bergamota, possuem um conjunto considerável de vitaminais e minerais, como a vitamina C, folato (B9), riboflavina (B2), niacina (B3), ácido pantotênico (B5), piridoxina (B6), assim como o magnésio, cobre, potássio, ferro, carotenoides provitamina $A$ e flavonoides (FRANKE, 2006).

Pesquisas revelam que a alimentação dos idosos também está relacionada a socialização com os familiares e amigos durante a refeição. $O$ autor expõe que na sua pesquisa uma grande parcela dos idosos não estavam satisfeitos com a própria 
alimentação devido à solidão, visto que $60 \%$ deles referiram sentir vontade de comer quando estão acompanhados (AIRES, 2019).

Levando em consideração o que foi citado anteriormente, e elencando com o recebimento de fotos e áudios enviado pelas funcionárias da instituição após a entrega de uma cesta de frutas cítricas, com laranja, bergamota e limão, foi evidenciado a alegria e satisfação das longevas depois do consumo em coletividade do mesmo, sendo solicitado que as alunas do presente grupo as presenteassem com mais frutas, estas vindas de pomares do interior do estado.

O Guia Alimentar para a População Brasileira (2014) mostra que morar em bairros ou territórios onde há feiras e mercados que comercializam frutas com boa qualidade torna mais fácil a adoção de padrões saudáveis de alimentação. Através da execução da ação extensionista, foi notado a necessidade de um engajamento dos órgãos municipais e da população da cidade como incentivadores da adoção de práticas saudáveis na alimentação e de campanhas de arrecadação de frutas e alimentos in natura para o auxílio no processo de envelhecimento das idosas do Lar.

\section{CONCLUSÃO}

Conclui-se ao descrever os aspectos nutricionais relacionados a ingesta de frutas cítricas, com um estímulo a longevidade com funcionalidade foi possível perceber o seu impacto de forma significativa e positiva no processo de senescência. Quando relacionado com a cultura, como o gauchesco no Rio Grande do Sul, onde as pessoas aguardam cobiçosamente a época de degustar as laranjas e bergamotas, torna-se uma tradição de excelente proveito para a adaptação de uma ingesta de frutas cítricas na rotina alimentar dos idosos, pela forma que essas fortalecem o sistema fisiológico, combatendo a solidão e proporcionando bem-estar.

\section{REFERÊNCIAS}


AIRES, I, O. et al. Consumo alimentar, estilo de vida e sua influência no processo de envelhecimento. Res., Soc. Dev. v. 8, n. 11, p. 1-19, 2019. Disponível em:<https://dialnet.unirioja.es/servlet/articulo?codigo=7164833>. Acesso em: 24/abril BRASIL. MINISTÉRIO DA SAÚDE. Guia alimentar para a população brasileira. 2 ed., p.16-22. Brasília: DF, 2014. Disponível em:< https://bvsms.saude.gov.br/bvs/publicacoes/guia alimentar populacao brasileira 2e d.pdf>. Acesso em: 18/maio.

FRANKE, S.I.R. Suco de laranja e vitamina C: efeito sobre a estabilidade genômica. UFRGS. p. 15-16. Porto Alegre: RS, 2006. Disponível em:https://www.lume.ufrgs.br/bitstream/handle/10183/7732/000554890.pdf?...1. Acesso em: 18/maio.

IBGE. Número de idosos cresce $18 \%$ em 5 anos e ultrapassa 30 milhões em 2017. Agência de Notícias, 2018. Disponível em:<https://agenciadenoticias.ibge.gov.br/agencia-noticias/2012-agencia-denoticias/noticias/20980-numero-de-idosos-cresce-18-em-5-anos-e-ultrapassa-30milhoes-em-2017>. Acesso em: 17/maio.

PEREIRA, I, F, S. SPYRIDES, M, H, C. ANDRADE, L, M, B. Estado nutricional de idosos no Brasil: uma abordagem multinível. Cad. Saúde Pública. v. 32, n. 5, p. 112, 2016. Disponível em:<https://www.scielo.br/scielo.php?pid=S0102311X2016000500709\&script=sci abstract\&tlng=pt>. Acesso em: 24/abril. SOUZA, M, A, H. et al. Perfil do estilo de vida de longevos. Revista Brasileira de Geriatria e Gerontologia. v. 19, n. 5, p. 819-826, 2016. Disponível em:<https://www.scielo.br/scielo.php?pid=S180998232016000500819\&script=sci arttext\&tlng=pt>. Acesso em: 24/abril. ZONE, B. Dieta das Zonas Azuis: segredos alimentares das pessoas que vivem há mais tempo no mundo. Disponível em:<https://www.bluezones.com/2020/07/blue-zones-diet-food-secrets-of-the-worldslongest-lived-people/>. Acesso em: 17/maio. 